Dr Stefano Sivolella, the leading author of the article, responds: We are very grateful to Dr Mc Crory for his question, which is an indication of his interest in the case we reported. One of the reviewers had raised the same point. In actual fact, as explained in the article (differential diagnosis), 'the general dental condition observed in the panoramic film could suggest a diagnosis of residual inflammatory cyst'. We might add a few comments: 1. The case described in our report was referred to us for the purposes of managing the late implantrelated complication, ie the penetration of the implant in a cavity. So, at the time of the treatment, the treatment of the cyst and the removal of the implant took priority. 2. After the treatment at our maxillofacial clinic, the patient's condition was monitored routinely. 3. The patient was warned about his poor state of general dental health and urged to see his own dentist to arrange for the necessary conservative, endodontic and prosthetic treatments.

DOI: $10.1038 /$ sj.bdj.2010.410

\section{DISCONTINUATION CONCERN}

Sir, as this issue has already been raised in the $B D J$, you may wish to publish the letter I received from the European Vice President and General Manager (UK) of Bristol-Myers Squibb Pharmaceuticals Limited (BMS), Frédéric Duchesne. Mr Duchesne has given his permission for this.

This was in response to a letter that Christine Randall and I sent on 7 December 2009 expressing our concerns about the discontinuation of this topical steroid agent.

E. A. Field

Liverpool

Dear Dr Field and Ms Randall, I would like to follow up on the letter I sent you on 22 December 2009 concerning the discontinuation of Adcortyl in Orabase, replying to the letter you have addressed to our Chairman and CEO, James Cornelius. I understand your concerns and disappointment that BMS has made the decision to discontinue the manufacture of Adcortyl in Orabase, and the impact this is having on patients' care. When discontinuing BMS products, we follow a procedure of informing a number of key stakeholders:

- Our local Regulatory Authorities (MHRA in the UK) - notifications were sent to the MHRA for the $10 \mathrm{~g}$ tubes in June 2008 (stock available until February 2009), and in July 2009 for the $5 \mathrm{mg}$ tubes (stock available until September 2009)

- Other key stakeholders (NHS, British National Formulary, MIMS, pharmaceutical journals) were informed of the discontinuation in order to notify their customers - in March 2009 and July 2009 for the $10 \mathrm{~g}$ and $5 \mathrm{~g}$ tubes respectively

- All doctors, pharmacists and patients who contacted us for information receive a formal response from our Medical Information department, by phone, email or letter.

To address the specific questions that were raised in your letter:

- As this is not a UK only decision but a global decision, we are not considering restarting production, and we will not be able to find any alternative source of supply within BMS

- We have been approached by a few companies which are interested in manufacturing and selling Adcortyl in Orabase. This is being handled by our divestiture team in the US. However, I cannot commit that this will move on positively, and I cannot commit any timing for this to happen. I have requested the divestiture team to keep us up to date on the progress they are making.

We have checked if similar products were still available outside of the UK, and we have found that the company Sigma in Australia/NZ and the company Taro in USA/Canada have products that are similar to Adcortyl in Orabase.

We understand that IDIS may be in a position to supply these similar products on a named patient basis. IDIS contact details are as follows: International Headquarters, Idis, Idis House, Churchfield Road, Weybridge, KT13 8DB.

Again, I understand your concerns, and I hope that this letter is addressing your specific request. Do not hesitate to contact me again if you need further information. DOI: 10.1038/sj.bdj.2010.411 